JRRD -

\title{
Do diabetic neuropathy patients benefit from balance training?
}

\author{
Mohammad Akbari, PhD; ${ }^{1}$ Hassan Jafari, PhD, PT; ${ }^{1 *}$ Afsaneh Moshashaee, MSc; ${ }^{1}$ Bijan Forugh, MD $^{\mathbf{2}}$ \\ Departments of ${ }^{1}$ Physical Therapy and ${ }^{2}$ Physical Medicine and Rehabilitation, Tehran University of Medical Sciences, \\ Tehran, Iran
}

\begin{abstract}
Peripheral neuropathy is a common complaint of diabetes. Peripheral neural damage in turn will cause balance impairments in diabetic patients. The purpose of this study was to investigate the effects of balance exercises on sway indices in diabetic patients with neuropathy. In this clinical trial study, 10 diabetic patients with peripheral neuropathy were recruited through simple nonprobability sampling along with 10 nondisabled aged-matched subjects. Participants in both groups were examined for balance abilities with the Biodex Balance System before intervention. The experimental group was tested again after intervention. Intervention consisted of progressive Biodex stability and rocker and wobble-board training for 10 sessions. All tests were done in eyes open and closed conditions with bilateral standing. After intervention, the experimental group was re-examined in the same way. Student and paired $t$-tests were used for data analysis. The overall stability index and anterior-posterior stability index were significantly decreased after treatment in the experimental group during different conditions. Balance indices in the experimental group were significantly higher than the control group before treatment. There was no significant difference in indices between the two groups after treatment. The results show that balance training can improve stability indices in diabetic patients with neuropathy.
\end{abstract}

Key words: balance disorder, balance training, diabetes, equilibrium, exercise, falling, neuropathy, physiotherapy, postural instability, stability indices.

\section{INTRODUCTION}

Diabetes is a complex metabolic disease that leads to impaired metabolism of carbohydrates, fats, and proteins [1]. The most common symptomatic complication is diabetic neuropathy, found in 50 percent of patients with diabetes over the age of 60 [2].

Polyneuropathy is a common problem for people with diabetes, leading to pain and impaired sensation and movement in the limbs, which in turn can cause leg ulcers [3]. Diabetic neuropathy plays a significant role in falling among elderly patients [4]; people with peripheral neuropathy caused by diabetes often experience balance disorder [5]. Postural sway in these patients is increased, especially with the eyes closed [6]. Peripheral neuropathy caused by diabetes causes significantly impaired sensation in the feet, reducing patients' ability to control their balance properly during daily activities [7]. Poor balance can be due to proprioception impairment [8]. Balance problems are also caused by movement-strategy impairment, biomechanical structural disorders, and disorientation [9].

Postural instability caused by peripheral neuropathy increases the impact of microtraumas and wounds [10]. In the elderly, slips or falls are one of the most common causes of injury or death [11]. People with diabetic neuropathy have balance disorders even with open eyes, making them vulnerable to falls [12].

\footnotetext{
Abbreviations: APSI $=$ anterior-posterior stability index, BBS = Biodex Balance System, LRST = left-right stability index, OSI = overall stability index.

* Address all correspondence to Hassan Jafari, PhD, PT; Department of Physical Therapy, Rehabilitation Faculty, Tehran University of Medical Sciences, PO Box 158754391, Mirdamad, Tehran, Iran; +98-21-2222-7124, ext 202; fax: +98-21-2222-0946. Email: $\underline{\text { h-jafari@tums.ac.ir }}$ http://dx.doi.org/10.1682/JRRD.2010.10.0197
} 
Proper postural control depends on the spatiotemporal coordination of information received from the vestibular, vision, and somatosensory systems. Damage to one or more of these systems increases the prevalence of falling in older people [13]. Aly et al. showed that patients with diabetic neuropathy had weaker stability measures in all balance indices compared with nondisabled subjects [14]. They also demonstrated that using visual inputs can improve balance among these patients. Emam et al. revealed that diabetic patients with neuropathy had significantly lower balance capability compared with diabetic patients without neuropathy [15].

Vibration [16-17] and passive tactile cues have been used to activate the sensory afferent system to improve balance in diabetic patients [18]. Aerobic exercise is also effective in reducing the risk or severity of peripheral neuropathy in patients [19]. Exercise therapy, including balance exercises, leads to increased oxygen pressure in the lower limbs, skin, and chests of diabetic patients, improving skin blood flow [20]. Group exercise therapy is effective in improving balance in older people and reduces the risk of falling [21].

Any changes in shear stress and pressure on the soles of the feet during standing tasks can stimulate mechanoreceptors to the higher nervous centers, which leads to increased balance ability in patients with diabetic neuropathy [16]. Therefore, the purpose of this study was first to evaluate balance disorders, then to assess the effects of stability exercises on balance indices in diabetic neuropathy patients, and finally to compare these patients with nondisabled age-matched people.

\section{METHODS}

\section{Design and Participants}

In this clinical trial study, 10 patients who met the inclusion criteria were recruited at the Endocrinology and Metabolism Centre at Firoozgar Hospital (Tehran, Iran) on a convenient sampling as the experimental group. Ten age-matched nondisabled subjects were selected as the control group. The inclusion criteria were age between 35 and 60 years, peripheral neuropathy confirmed by electrodiagnostic tests, and the ability to stand on both feet and on one leg. The exclusion criteria were diabetic ulcers in either foot, lack of blood sugar control, internal ear infections, other nervous system impairments (except neuropathy) or other diseases affecting balance, musculo- skeletal problems such as vertebral column and limb deformity, history of repeated ankle sprains in the year before, severe pain influencing balance, visual problems (inability to see the stabilometer cursor), and the existence of any other factors that interfere with balance except diabetic neuropathy. Not participating regularly in therapy sessions or unwillingness to be in the study led to the exclusion of patients from the investigation.

Data were recorded through interviews and balance tests. Balance ability was measured in different situations with the Biodex Balance System (BBS) (model 302-945; Shirley, New York). Balance tests in the experimental group were performed before and after treatment. Overall stability index (OSI), an index of deviation in any direction from the horizontal plane on the BBS plate; anteriorposterior stability index (APSI), an index of deviation on the BBS plate in sagittal plane; and left-right stability index (LRSI), a deviation on the BBS plate on the frontal plane, were measured. The study design is shown in the Figure.

\section{Measurements}

Each subject was tested in six modes: standing on two legs with eyes both open and closed and standing on one leg at a time with eyes both open and closed. Dynamic stability tests were conducted in each mode. All tests and familiarization with the stabilometer machine lasted $45 \mathrm{~min}$ for each subject. Subjects were told that each test would be conducted once for familiarity.

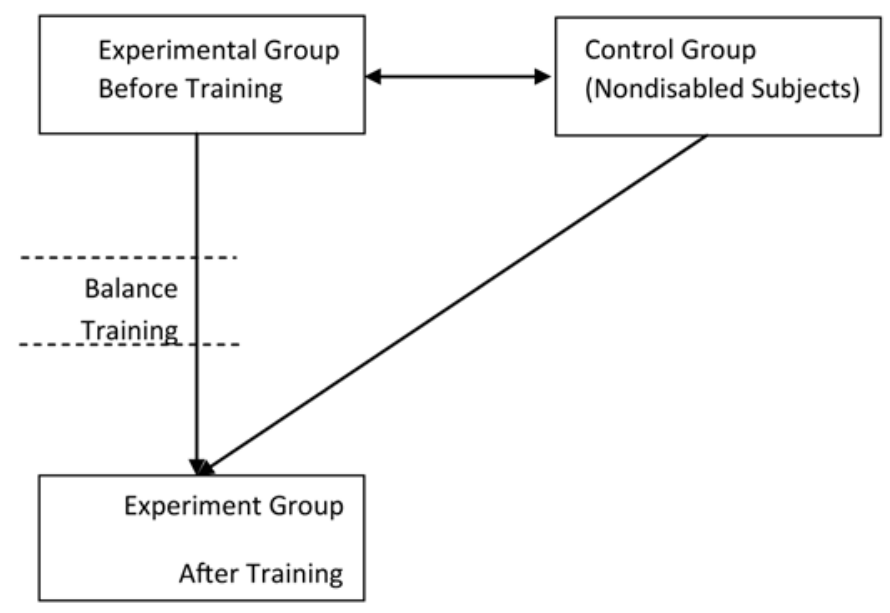

Figure.

Study design. 
Then, while wearing comfortable clothing and with bare feet, subjects stood on the platform and concentrated on the screen in front of them. The first test was conducted standing on both feet for $20 \mathrm{~s}$ with open eyes. The stability level indicating the firmness of the platform was set on 8 during the test, where 8 is the most rigid and 1 the least rigid setting.

While the subject stood in the middle of the platform, he/she was told the platform would release in a moment. Then the subject was told to try to hold the cursor in the middle of a target circle of the monitor. The placement of the feet on the platform was then fixed and the status of the feet was saved on the device.

The first test was performed for familiarity, and then each test was performed three times with 1 min of rest in between. Each test took $20 \mathrm{~s}$. During the test, the subject was told to keep the cursor in the middle of co-centered circles. OSI, APSI, and LRSI were measured. For each mode, the average of three tests was considered the subject index.

\section{Balance Exercise Using Biodex Balance System}

The BBS was used for balance training in the experimental group. The subjects had to stand on the platform and try to keep the cursor in the middle of co-centered circles on the monitor with their eyes open or use their proprioception with closed eyes to keep their equilibrium on the force platform. The platform stability level was set on 8 for the first two sessions and was reduced one level every two sessions so that in the ninth and tenth sessions the stability level was 4 . From session four on, the subjects also performed the limits of stability exercise with BBS. This exercise was performed two times in each session.

\section{Balance Exercise with Rocker and Wobble Board}

Subjects performed balance training exercises on rocker and wobble boards with open and closed eyes. The rocker-board exercise was performed in both dorsi-plantar and left-right directions. Each exercise was performed five times and took $15 \mathrm{~s}$ each with $45 \mathrm{~s}$ rest intervals. The exercise duration increased $5 \mathrm{~s}$ and rest interval decreased 5 s every two sessions.

\section{Statistical Analysis}

Data were collected over 5 months, and analysis was conducted using SPSS software version 15.0 (SPSS Inc; Chicago, Illinois). Normal distribution using the Kolmo-
grov-Smirnov analysis was done. The independent samples $t$-test was used for comparing the control and experimental groups. The paired $t$-test was used to compare balance indices before and after training in the experimental group. Statistical significance for all tests was accepted below 0.05 .

\section{RESULTS}

Table 1 shows the demographics and characteristics of both groups. Paired $t$-test analysis of OSI, APSI, and LRSI showed significant decreased in subjects' scores after training with open eyes in comparison with before training. The OSI decreased from $2.76 \pm 0.81$ to $1.92 \pm$ $0.38(p<0.01)$. The stability indices were almost the same for closed eyes, except for LRSI (Table 2).

The independent samples $t$-tests of OSI with open eyes on both feet between the experimental and control groups before training were significantly different $(p=$ 0.006). The difference between the control and experimental groups was not significant after training ( $p=$ 0.71) (Table 2).

\section{DISCUSSION}

The purposed of this study was to determine the effect of balance exercise on stability indices of patients with diabetic neuropathy and compare them with the control group. To evaluate this effect, primarily we had to determine whether balance was significantly different between nondisabled and diabetic neuropathy patients.

Table 1.

Demographic characteristics of participants $(n=10)$.

\begin{tabular}{lcc}
\hline Characteristic & $\begin{array}{c}\text { Control } \\
\text { (Mean } \pm \text { SD) }\end{array}$ & $\begin{array}{c}\text { Experimental } \\
\text { (Mean } \pm \text { SD) }\end{array}$ \\
\hline Age $(\mathrm{yr})$ & $56.20 \pm 3.22$ & $55.80 \pm 3.85$ \\
Height $(\mathrm{cm})$ & $160.80 \pm 8.02$ & $162.10 \pm 9.92$ \\
Weight $(\mathrm{kg})$ & $64.50 \pm 10.53$ & $73.50 \pm 10.26$ \\
FBS $(\mathrm{mg} / \mathrm{dL})$ & Normal & $221.80 \pm 78.54$ \\
NCV $(\mathrm{m} / \mathrm{s})$ & Normal & $30.22 \pm 1.20$
\end{tabular}

$\overline{\text { FBS }=\text { fasting blood sugar, NCV }=\text { nerve conduction velocity, } \mathrm{SD}=\text { standard }}$ deviation. 
JRRD, Volume 49, Number 2, 2012

Table 2.

Comparison of stability indices between groups (control and experimental) before and after balance training and within group (experimental) before and after balance training.

\begin{tabular}{|c|c|c|c|c|c|c|}
\hline Index & Control & $\begin{array}{c}\text { Experimental } \\
\text { Before } \\
\text { Training }\end{array}$ & $\begin{array}{c}\text { Experimental } \\
\text { After } \\
\text { Training }\end{array}$ & $\begin{array}{c}p \text {-Value Between } \\
\text { Groups Before } \\
\text { Training }\end{array}$ & $\begin{array}{c}p \text {-Value Between } \\
\text { Groups After } \\
\text { Training }\end{array}$ & $\begin{array}{c}p \text {-Value } \\
\text { Within } \\
\text { Experimental }\end{array}$ \\
\hline \multicolumn{7}{|l|}{ Open Eyes } \\
\hline OSI & $1.85 \pm 0.43$ & $2.76 \pm 0.81$ & $1.92 \pm 0.38$ & 0.006 & 0.71 & $<0.01$ \\
\hline APSI & $1.42 \pm 0.43$ & $2.35 \pm 0.84$ & $1.48 \pm 0.46$ & 0.006 & 0.77 & 0.001 \\
\hline LRSI & $1.33 \pm 0.44$ & $1.67 \pm 0.42$ & $1.28 \pm 0.28$ & 0.11 & 0.77 & $<0.001$ \\
\hline OSI & $3.14 \pm 1.09$ & $6.51 \pm 1.59$ & $4.30 \pm 1.28$ & 0.0001 & 0.043 & $<0.001$ \\
\hline APSI & $2.20 \pm 0.83$ & $4.78 \pm 1.67$ & $2.53 \pm 1.10$ & 0.0001 & 0.462 & $<0.001$ \\
\hline LRSI & $2.29 \pm 0.84$ & $4.33 \pm 1.22$ & $3.50 \pm 1.13$ & 0.0001 & 0.014 & 0.12 \\
\hline
\end{tabular}

\section{Comparisons of Groups Before Training}

OSI and APSI in bilateral standing with open and closed eyes showed significant differences before exercise intervention between the experimental and control groups. This difference demonstrated lower balance ability in patients with diabetic neuropathy according to balance indices, which is consistent with previous studies [1,4-6,10,12,14-15,22-23]. Aly et al. reported significant differences between the stability indices (OSI, APSI, and LRSI) of control and diabetic neuropathy patients, with both open and closed eyes [1]. Corriveau et al. showed that neuropathy's intensity level significantly correlates with balance deficits [2].

LRSI did not show significant difference between the control and experimental groups during the open-eyes test, but did show a significant difference in the closedeyes test before training. This could be because of the intensity level of diabetic neuropathy, which could differ between studies. It is expected that even LRSI with open eyes can be affected in severe conditions of neuropathy in lower limbs.

\section{Comparisons of Groups After Training}

All indices in open-eye conditions showed no significant difference between the control and experimental groups after training. APSI with closed eyes also showed no change between the two groups. These findings support the idea that balance training can improve the balance ability of neuropathic diabetic patients. Previous studies have also emphasized the positive effects of balance training exercises on stability and body stability [16, 19-24]. The effect of vibration and passive sensory cues on improving balance abilities among diabetic patients also have been reported [16-18]. We believe that both vibration and exercise can activate the afferent sensory input, but that exercise additionally can make the patient actively exert the motor response and necessary movement in reaction to sensory demand. In this way, the afferent motor system also could be trained and improved.

OSI and LRSI demonstrated significant differences between the control and experimental groups after training with closed eyes. This shows that these two index scores were not improved enough by the training exercises to make the two groups alike. We believe that for closed eyes conditions, more balance training exercises would be needed to achieve optimum balance control. This result is the same as that reported by Arnold and Schmitz [25].

\section{Comparisons Within Groups}

OSI and APSI showed significant differences before and after training in bilateral standing in open- and closed-eyes conditions. Only LRSI was not significant for the same setting. We believe that APSI is more related to the activation of ankle and sole muscles. These distal limb muscles and their nerves could be affected by diabetic neuropathy more than the proximal body muscles. Left-right stability is mainly provided by the hip abductor and adductor muscles. These proximal muscles and their nerves are rarely impaired in diabetic disease. This could be the reason for no significant change in LRSI before and after training in the present study. This finding was consistent with the study conducted by Aly et al., which showed OSI and APSI have a stronger positive correlation 
with neuropathy in lower limbs [1]. Arnold and Schmitz reported that overall stability is a combination of leftright and anterior-posterior stability elements, but the role of the anterior-posterior stability is more prominent in overall stability [25].

\section{CONCLUSIONS}

According to the present study findings, diabetic patients who experience peripheral neuropathy and consequent balance problems can achieve better balance and stability through progressive balance training with emphasis on the anterior-posterior neuromuscular elements of stability. These patients are more reliant on visual inputs, which causes them greater balance problems during closed-eye tests. Based on the findings, we recommend more emphasis on closed-eye exercises. This training should be gradual and persistent so as to have a long-term effect on the patients.

\section{AKNOWLEDGMENTS}

\author{
Author Contributions: \\ Study concept and design: M. Akbari, A. Moshashaee, B. Forugh. \\ Acquisition of data: A. Moshashaee. \\ Analysis and interpretation of data: H. Jafari, A. Moshashaee. \\ Drafting of manuscript: H. Jafari, M. Akbari. \\ Critical revision of manuscript for important intellectual content: \\ H. Jafari, M. Akbari. \\ Statistical analysis: H. Jafari. \\ Study supervision: M. Akbari, B. Forugh.
}

Financial Disclosures: The authors have declared that no competing interests exist.

Funding/Support: The authors appreciate the help of the Rehabilitation Research Center of Tehran University of Medical Sciences for providing the place and necessary equipment for data collection. This research was conducted with the financial support of Tehran University of Medical Sciences.

Additional Contributions: Hassan Jafari is currently affiliated with the University of Leuven, Belgium.

Institutional Review: This research was approved by the Research Ethics Committee of Rehabilitation Sciences Faculty, Tehran University of Medical Sciences. All participants gave informed consent.

Participant Follow-Up: The authors do not plan to inform participants of the publication of this study. However, participants have been encouraged to check the study Web site for updated publications.

\section{REFERENCES}

1. Aly FA, El-Saed AA, Hatab KF. Assessment of stabilitydefects in patient with diabetic peripheral neuropathy. Bull Faculty Physical Ther Cairo University. 2008;13(1):29-40.

2. Corriveau H, Prince F, Hébert R, Raîche M, Tessier D, Maheux P, Ardilouze JL. Evaluation of postural stability in elderly with diabetic neuropathy. Diabetes Care. 2000;23(8): 1187-91. PMID:10937520 http://dx.doi.org/10.2337/diacare.23.8.1187

3. Chalk C, Benstead TJ, Moore F. Aldose reductase inhibitors for the treatment of diabetic polyneuropathy. Cochrane Database Syst Rev. 2007;17(4):CD004572. PMID:17943821

4. Maurer MS, Burcham J, Cheng H. Diabetes mellitus is associated with an increased risk of falls in elderly residents of a long-term care facility. J Gerontol A Biol Sci Med Sci. 2005;60(9):1157-62. PMID:16183956 http://dx.doi.org/10.1093/gerona/60.9.1157

5. Uccioli L, Giacomini PG, Monticone G, Magrini A, Durola L, Bruno E, Parisi L, Di Girolamo S, Menzinger G. Body sway in diabetic neuropathy. Diabetes Care. 1995;18(3): 339-44. PMID:7555477 http://dx.doi.org/10.2337/diacare.18.3.339

6. Ahmmed AU, Mackenzie IJ. Posture changes in diabetes mellitus. J Laryngol Otol. 2003;117(5):358-64. PMID:12803785 http://dx.doi.org/10.1258/002221503321626393

7. Boucher P, Teasdale N, Courtemanche R, Bard C, Fleury M. Postural stability in diabetic polyneuropathy. Diabetes Care. 1995;18(5):638-45. PMID:8586001 http://dx.doi.org/10.2337/diacare.18.5.638

8. Akbari M, Karimi H, Farahini H, Faghihzadeh S. Balance problems after unilateral lateral ankle sprains. J Rehabil Res Dev. 2006;43(7):819-24.PMID:17436168 http://dx.doi.org/10.1682/JRRD.2006.01.0001

9. De Oliveira CB, De Medeiros IR, Frota NA, Greters ME, Conforto AB. Balance control in hemiparetic stroke patients: main tools for evaluation. J Rehabil Res Dev. 2008; 45(8):1215-26. PMID:19235121 http://dx.doi.org/10.1682/JRRD.2007.09.0150

10. Katoulis EC, Ebdon-Parry M, Hollis S, Harrison AJ, Vileikyte L, Kulkarni J, Boulton AJ. Postural instability in diabetic neuropathic patients at risk of foot ulceration. Diabet Med. 1997;14(4):296-300. PMID:9113483 http://dx.doi.org/10.1002/(SICI)10969136(199704)14:4<296::AID-DIA344>3.0.CO;2-5

11. Kim BJ, Robinson CJ. Effects of diabetic neuropathy on body sway and slip perturbation detection in older population. Int J Occup Saf Ergon. 2006;12(3):241-54.

PMID:16984784 
12. Speers RA, Kuo AD, Horak FB. Contributions of altered sensation and feedback responses to changes in coordination of postural control due to aging. Gait Posture. 2002;16(1):20-30. PMID:12127183 http://dx.doi.org/10.1016/S0966-6362(02)00003-6

13. Priplata A, Niemi J, Veves A, Lipsitz L, Collins J. Vibrating insoles improve balance in diabetic patients with peripheral neuropathy. Med Sci Sports Exerc. 2004;36(5):S6.

14. Aly FA, Fawzy E, Ibrahim E, Mohamed M. Assessment of stability deficits in patients with diabet peripheral neuropathy. Bull Faculty Phys Therapy Cario University. 2007;12(1):31-42.

15. Emam AA, Gad AM, Ahmed MM, Assal HS, Mousa SG. Quantitative assessment of posture stability using computerised dynamic posturography in type 2 diabetic patients with neuropathy and its relation to glycaemic control. Singapore Med J. 2009;50(6):614-18. PMID:19551316

16. Hijmans JM, Geertzen JH, Zijlstra W, Hof AL, Postema K. Effects of vibrating insoles on standing balance in diabetic neuropathy. J Rehabil Res Dev. 2008;45(9):1441-49. PMID:19319766 http://dx.doi.org/10.1682/JRRD.2008.02.0023

17. Priplata AA, Niemi JB, Harry JD, Lipsitz LA, Collins JJ. Vibrating insoles and balance control in elderly people. Lancet. 2003;362(9390):1123-24. PMID:14550702 http://dx.doi.org/10.1016/S0140-6736(03)14470-4

18. Menz HB, Lord SR, Fitzpatrick RC. A tactile stimulus applied to the leg improves postural stability in young, old and neuropathic subjects. Neurosci Lett. 2006;406(1-2): 23-26. PMID:16904264 http://dx.doi.org/10.1016/j.neulet.2006.07.014

19. Balducci S, Iacobellis G, Parisi L, Di Biase N, Calandriello E, Leonetti F, Fallucca F. Exercise training can modify the natural history of diabetic peripheral neuropathy. J Diabetes Complications. 2006;20(4):216-23. PMID:16798472 http://dx.doi.org/10.1016/j.jdiacomp.2005.07.005

20. Williams DT, Harding KG, Price PE. The influence of exercise on foot perfusion in diabetes. Diabet Med. 2007;24(10): 1105-11. PMID:17593240 http://dx.doi.org/10.1111/j.1464-5491.2007.02218.x
21. Robitaille Y, Laforest S, Fournier M, Gauvin L, Parisien M, Corriveau H, Trickey F, Damestoy N. Moving forward in fall prevention: An intervention to improve balance among older adults in real-world settings. Am J Public Health. 2005;95(11):2049-56. PMID:16195514 http://dx.doi.org/10.2105/AJPH.2004.057612

22. Oppenheim U, Kohen-Raz R, Alex D, Kohen-Raz A, Azarya M. Postural characteristics of diabetic neuropathy. Diabetes Care. 1999;22(2):328-32. PMID:10333953 http://dx.doi.org/10.2337/diacare.22.2.328

23. Lafond D, Corriveau H, Prince F. Postural control mechanisms during quiet standing in patients with diabetic sensory neuropathy. Diabetes Care. 2004;27(1):173-78. PMID:14693985 http://dx.doi.org/10.2337/diacare.27.1.173

24. Akhbari B, Ebrahimi TI, Salavati M, Sanjari MA. A 4week Biodex stability exercise program improved ankle musculature onset, peak latency and balance measures in functionally unstable ankles. Phys Ther Sport. 2007;8(3): 117-29. http://dx.doi.org/10.1016/j.ptsp.2007.03.004

25. Arnold BL, Schmitz RJ. Examination of balance measures produced by the Biodex Stability System. J Athl Train. 1998;33(4):323-27. PMID:16558529

Submitted for publication October 11, 2010. Accepted in revised form June 8, 2011.

This article and any supplementary material should be cited as follows:

Akbari M, Jafari H, Moshashaee A, Forugh B. Do diabetic neuropathy patients benefit from balance training? J Rehabil Res Dev. 2012;49(2):333-38.

http://dx.doi.org/10.1682/JRRD.2010.10.0197

ResearcherID: Hassan Jafari, PhD, PT: A-2396-2012

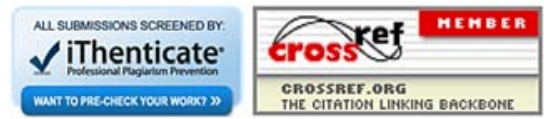

